\title{
Neurochemistry of Idiopathic Restless Legs Syndrome
}

\author{
Félix Javier Jiménez-Jiménez, ${ }^{1}$ Hortensia Alonso-Navarro, ${ }^{2}$ Elena García-Martín ${ }^{3}$ and José AG Agúndez ${ }^{4}$ \\ 1. Chairman of the Section of Neurology; Professor of Neurology, Hospital Universitario del Sureste, Arganda del Rey, Madrid, Spain; \\ 2. Consultant Neurologist, Section of Neurology, Hospital Universitario del Sureste, Arganda del Rey, Madrid, Spain; 3. Professor of Pharmacology, \\ Universidad de Extremadura, Cáceres, Spain; 4. Full Professor of Pharmacology, Universidad de Extremadura, Cáceres, Spain.
}

\begin{abstract}
The pathogenesis of idiopathic restless legs syndrome (iRLS) is not well established, but the most important hypothesis suggests dopaminergic dysfunction and iron deficiency. However, recent reports suggest a possible role for several neurotransmitters or neuromodulators, such as aspartate, glutamate, gamma-hydroxybutyric acid (GABA) and opiates, as well as relation with vitamin D deficiency. In this review, we summarise the studies related to neurochemical findings in iRLS.
\end{abstract}

\section{Keywords}

Restless legs syndrome, pathogenesis, neurochemistry, neurotransmitters, dopaminergic dysfunction, iron deficiency

Disclosures: Félix Javier Jiménez-Jiménez, Hortensia Alonso-Navarro, Elena García-Martín and José AG Agúndez have no conflicts of interest to declare. Research at the authors' laboratories is financed by grants PI12/00241, PI12/00324 and RETICS RD12/0013/0002 from Fondo de Investigación Sanitaria, Instituto de Salud Carlos III, Spain Innovation and GR10068 from Junta de Extremadura, Spain. Financed in part by FEDER funds from the European Union. No funding was received for the publication of this article.

Open Access: This article is published under the Creative Commons Attribution Noncommercial License, which permits any non-commercial use, distribution, adaptation and reproduction provided the original author(s) and source are given appropriate credit.

Received: 26 January 2015 Accepted: 6 March 2015 Citation: European Neurological Review, 2015;10(1):35-44 DOl: 10.17925/ENR.2015.10.01.35

Correspondence: Félix Javier Jiménez-Jiménez, C/Marroquina 14, 3 B, E-28030 Madrid, Spain E: fjavier.jimenez@salud.madrid.org; felix.jimenez@sen.es

First described by Willis in 1672 and described in more detail by Ekbom in 1945, restless legs syndrome (RLS) or Willis-Ekbom disease (WED) is defined as a sensorimotor disorder in which the initial sensory symptom consists of an irresistible urge to move the legs (or both the legs and the arms) and is accompanied by or causes unpleasant sensations, appearing or worsening during rest, improving totally or partially with movement of the legs (or both the legs and the arms) and occurring only at, or worsening towards, evening and night. ${ }^{1}$ Together with these major diagnostic criteria, three other criteria are classically considered supportive (but not diagnostically necessary) diagnostic criteria for RLS, including positive family history for RLS, response to dopaminergic drugs and presence of periodic limb movements (PLMS), assessed by leg activity devices or polysomnography while awake or during sleep. ${ }^{1}$ The 2014 Revised International Restless Legs Syndrome Study Group (IRLSSG) Diagnostic Criteria for RLS introduced as the fifth essential criterion the requirement that the above clinical features not be related to other medical or behavioural conditions, often referred to as "RLS mimics" - such as myalgia, venous stasis, leg oedema, arthritis, leg cramps, positional discomfort or habitual foot tapping (symptoms commonly confused with RLS) - and added course specifiers to classify RLS as chronic-persistent versus intermittent symptoms, and for clinical significance of RLS. ${ }^{2}$

Although the exact pathophysiology of idiopathic RLS (iRLS) is not well established, dopaminergic dysfunction and brain iron insufficiency are the most accepted theories. In this review, we summarise the main findings related to neurochemistry and biochemical findings of iRLS.

\section{Search Strategy}

References for this review were identified through a PubMed search that included the period from 1966 until 5 March 2015. The term "restless legs syndrome" was crossed with "neurochemistry", "biochemistry", "neurotransmitters", "dopamine", "noradrenaline", "norepinephrine", "adrenaline", "epinephrine", "serotonin", "GABA", "glycine", "glutamate", "neuropeptides", "iron", "ferritin", "transferrin", "white matter", "grey matter" and "transcranial magnetic stimulation". This search retrieved 1,480 references that were examined one-for-one, with those strictly related to neurochemical findings in IRLS $(n=109)$ selected. This review aims to provide an extensive descriptive review of studies published on this topic, to summarise the main conclusions and to propose suggestions for future studies.

\section{Dopaminergic Dysfunction}

The excellent therapeutic response of RLS to dopaminergic drugs, together with some neuropathological, neuroimaging, biochemical and experimental data, supports the possible role of the dopaminergic system in the pathophysiology of RLS.

\section{Neuropathological Data}

To date, only a few post-mortem studies have focused on the dopaminergic system in iRLS. Connor et al. ${ }^{3}$ described similar tyrosinehydroxylase (TH) staining in the substantia nigra of seven RLS patients compared with five controls in one study, a finding confirmed by Walters et al. ${ }^{4}$ However, in a further study analysing the substantia nigra and putamen of eight iRLS female patients, the substantia nigra of eight female controls and the putamen of seven female controls, these authors reported ${ }^{5}$ 
(a) A significant increase in TH staining in the substantia nigra, but not the putamen, of iRLS patients

(b) A significant increase of phosphorylated or active $\mathrm{TH}$ in the substantia nigra of iRLS patients

(C) A significant decrease in dopamine $\mathrm{D}_{2}$ receptors $\left(\mathrm{DRD}_{2}\right)$ in the putamen of iRLS patients, correlated with RLS severity

(d) Normality of DRD, receptors, dopamine transporters and vesicular monoamine transporter (VMAT) in the putamen and the substantia nigra of iRLS patients

Because the alterations found in the study by Connor et al. ${ }^{3}$ are similar to those found in animal and cell models of iron insufficiency, the authors hypothesised that dopaminergic abnormality in IRLS was owing to a primary iron insufficiency.

Earley et al. ${ }^{6}$ found no significant differences in TH staining cell volume, fractional glial fibrillary acidic protein (GFAP) staining or general histological examination in the diencephalic-spinal A11 system in six iRLS patients and six controls.

\section{Functional Studies on the Dopaminergic System}

The results of functional studies on the dopaminergic system, including both studies on the presynaptic terminal and studies of postsynaptic $\mathrm{DRD}_{2}$, are summarised in Table 1.

Many of these studies found no significant differences in the binding of the tracer to the presynaptic dopaminergic terminal, ${ }^{7-10,12}$ whereas others found a mild reduction in the entire striatum or only in caudate or putamen, ${ }^{13-15}$ and other studies described a mild increased density in the striatum. ${ }^{11}$

Studies on the post-synaptic $\mathrm{DRD}_{2}$ performed using SPECT with ${ }^{123}$-S-2hydroxy-3-iodo-6-methoxy-[(1-ethyl-2-pyrrolidinyl)methyl] benzamide (IBZM) showed similar binding in the striatum of IRLS patients and controls, $7,1,1,6,17$ save for one that found decreased binding. ${ }^{9}$ However, the majority of studies on $\mathrm{DRD}_{2}$ using the tracer ${ }^{11} \mathrm{C}$-raclopride found decreased binding or increased availability in the entire striatum ${ }^{13,18,20}$ or only in the caudate nucleus. ${ }^{19}$

\section{Cerebrospinal Fluid Dopamine Metabolite Levels}

Several studies assessed cerebrospinal fluid (CSF) levels of dopamine metabolites in RLS patients compared with controls:

(a) Earley et al..$^{23}$ described CSF homovanillic acid (HVA) levels in 16 iRLS patients 2 weeks off medication (samples obtained at 10 a.m.) similar to that in 14 healthy (not age-matched) controls, whereas neopterin and tetrahydrobiopterin $\left(\mathrm{BH}_{4}\right)$ levels were increased in iRLS patients. The same group, in a further study involving 30 iRLS patients and 22 controls, using CSF samples obtained at 10 p.m., found higher 3-orthomethyl-DOPA (3-OMD) and similar HVA and $\mathrm{BH}_{4}$ levels in iRLS patients compared with controls, as well as higher CSF HVA/5-hydroxyindoleacetic acid (5-HIAA) ratio, $\mathrm{BH}_{4}$ and 3-OMD levels in this cohort of $\mathrm{IRLS}$ patients compared with those of the previous study with samples obtained at 10 a.m., suggesting changes having to do with the circadian rhythm. ${ }^{24}$

(b) Stiasny-Kolster et al. ${ }^{25}$ found similar CSF HVA, 3-OMD, $\mathrm{BH}_{4^{\prime}}$ dihydrobiopterin, neopterin and methyltetrahydrofolate levels in 22 drug-naive RLS patients and 11 healthy controls.

(c) Poceta et al. ${ }^{26}$ monitored for 22 hours CSF dopamine (DA), HVA, dihydroxy-phenylacetic acid (DOPAC) and 5-HIAA from samples every 30 minutes, and hypocretin-1 from samples every 60 minutes, in three iRLS patients and three controls, measuring CSF levels of hypocretin-1 as well. There was a peak for DA at 10 a.m. $(p<0.025)$ and for HVA at 2 p.m. $(p<0.01)$, but no evidence of a significant 24-h rhythm for DOPAC, 5-HIAA, the HVA/5-HIAA ratio, or hypocretin-1. These results demonstrate a circadian rhythm for CSF DA and HVA concentrations in humans (which could be related to the circadian rhythm of RLS symptoms), with higher levels in the day than at night.

(d) Allen et al. ${ }^{77}$ reported higher CSF HVA levels in iRLS patients having high CSF 3-OMD ( $n=30)$, and lower CSF HVA levels in RLS patients having normal CSF 3-OMD ( $n=19)$, when compared with controls $(n=36)$, as well as higher PLMS/hour for iRLS patients having high CSF 3-OMD (suggesting higher severity of RLS) than for those having normal CSF 3-OMD, suggesting increased DA synthesis for more severe RLS.

\section{Experimental Models Related to the Dopaminergic System}

After stereotactic injection of the fluorescent tracer Fluoro-Gold (FG) in the dorsolumbar spinal cord of mice, this tracer reached the dopaminergic neurons within the A10 and A11 areas or diencephalic (dorsoposterior hypothalamus) spinal neurons. ${ }^{28}$ Similarly, unilateral injection of FG into the cervical spinal cord of nonhuman primates labelled $A 11$ neurons. ${ }^{29}$ In addition, DRD ${ }_{1}$ mRNA is absent and $\mathrm{DRD}_{2}$ and $\mathrm{DRD}_{5}$ mRNAs are expressed in the dorsal horn and $\mathrm{DRD}_{3}$ in both the dorsal and ventral horns of nonhuman primates. ${ }^{29}$ These data demonstrated the existence of a dopaminergic diencephalic-spinal pathway. However, although the blockade of $\mathrm{DRD}_{2}$ with raclopride increases the DOPAC/DA ratio in the striatum and nucleus accumbens of rats, it has no effect in the spinal cord, and pretreatment using a $\mathrm{DRD}_{2}$ agonist does not prevent increase in DA concentrations in the spinal cord elicited with gamma-butyrolactone, suggesting that diencephalic-spinal DA neurons lack presynaptic synthesis modulating $\mathrm{D}_{2}$ autoreceptors. ${ }^{30}$

Stereotactic bilateral 6-hydroxydopamine (6-OHDA) lesions in the A11 area in rodents induce increased locomotor activity partially resembling symptoms of RLS in humans, ${ }^{31-34}$ more markedly so in those animals pretreated with iron-deficiency (ID) diet, ${ }^{32-34}$ and can be reversed using the $\mathrm{DRD}_{2} / \mathrm{DRD}_{3}$ agonists ropinirole ${ }^{32,33}$ and pramipexole. ${ }^{34}$ Such lesions induced the following neuropathological and neurochemical changes:

(a) Decreased by 54-94 \% of TH staining cells, ${ }^{31,33}$ especially in ID diet animals, ${ }^{33}$ which were reversed by ropinirole and worsened by $\mathrm{DRD}_{1}$ agonists. ${ }^{33}$

(b) Decreased DA levels in the lumbar spinal cord. ${ }^{32}$

(c) Decreased $\mathrm{DRD}_{2} / \mathrm{DRD}_{3}$ mRNA and protein levels and binding capacity in the lumbar spinal cord without changes in DRD, binding. $\mathrm{DRD}_{2}$ binding was even lower in ID diet animals. ${ }^{32,34}$

$\mathrm{DRD}_{3}$ knockout mice display hyperactivity and increased locomotor activity resembling features of patients who have RLS. Low dopamine levels decrease monosynaptic stretch reflexes (MSR) and increase the latency of reflex amplitude in wild mice and increased them in $\mathrm{DRD}_{3}$ knockout mice, whereas $\mathrm{DRD}_{3}$ agonists reduce and $\mathrm{DRD}_{3}$ antagonists increase the MSR in wild mice and have no effect in $\mathrm{DRD}_{3}$ knockout mice. ${ }^{35}$ These data suggest a role of $\mathrm{DRD}_{3}$ in modulating spinal 
Table 1: Results of Functional Imaging Studies Using Dopamine, Serotonin and Opiate Tracers in Patients with Idiopathic Restless Legs Syndrome Compared with Controls

\begin{tabular}{|c|c|c|c|c|}
\hline & Method & Authors, YearRef & RLS/Controls & Main Findings \\
\hline \multirow[t]{9}{*}{$\begin{array}{l}\text { Presynaptic DA } \\
\text { terminal }\end{array}$} & \multirow[t]{2}{*}{${ }^{123 \mid-I P T-S P E C T}$} & Eisensehr et al., $2001^{7}$ & $\begin{array}{l}25 \text { (14 drug-naive and } 11 \\
\text { levodopa-treated)/10 }\end{array}$ & Nonsignificant differences between groups \\
\hline & & Linke et al., $2004^{8}$ & $28 / 23$ & Nonsignificant differences between groups \\
\hline & \multirow[t]{3}{*}{ 123|-beta-CIT-SPECT } & Michaud et al., $2002^{9}$ & 10 (drug-naive)/10 & Nonsignificant differences between groups \\
\hline & & Mrowka et al., $2005^{10}$ & $6 / ?$ & Nonsignificant differences between groups \\
\hline & & Kim et al., $2012^{11}$ & $13 / 12$ & $\begin{array}{l}\text { Increased DAT density in the caudate }(p=0.037) \text {, posterior } \\
\text { putamen }(p=0.041) \text {, and entire striatum }(p=0.046)\end{array}$ \\
\hline & ${ }^{18}$ Fluoro-L-dopa & Trenkwalder et al., $1999^{12}$ & $4 / 10$ & Nonsignificant differences between groups \\
\hline & \multirow[t]{2}{*}{ (F-DOPA) PET } & Turjanski et al., $1999^{13}$ & $13 / 14$ & Mild reduction of binding in the putamen $(p=0.04)$ \\
\hline & & Ruottinen et al., $2000^{14}$ & 9 (drug-naive)/27 & $\begin{array}{l}\text { Mild reduction of binding in caudate ( } 88 \% \text { ) and } \\
\text { putamen ( } 89 \%)\end{array}$ \\
\hline & ${ }^{11} \mathrm{C}$-methylphenidate PET & Earley et al., $2011^{15}$ & $36 / 34$ & $\begin{array}{l}\text { Decreased DAT binding in the striatum (putamen and } \\
\text { caudate but not the ventral striatum) in both day and } \\
\text { night scans } \\
\text { Lack of correlation of DAT binding potentials with any } \\
\text { clinical measures of RLS }\end{array}$ \\
\hline \multirow[t]{10}{*}{$\begin{array}{l}\text { Postsynaptic } \\
\text { DA terminal }\end{array}$} & \multirow[t]{5}{*}{$\begin{array}{l}\text { 123/-IBZM-SPECT (striatal } \\
\mathrm{D}_{2} \text { receptors) }\end{array}$} & Eisensehr et al., $2001^{7}$ & $\begin{array}{l}25 \text { (14 drug-naive and } 11 \\
\text { levodopa-treated)/10 }\end{array}$ & Nonsignificant differences between groups \\
\hline & & Tribl et al., $2001^{16}$ & $14 / 9$ & Nonsignificant differences between groups \\
\hline & & Michaud et al., $2002^{9}$ & 10 (drug-naive)/10 & Decreased binding in RLS ( $p=0.006)$ \\
\hline & & Tribl et al., $2004^{17}$ & 14 (all with PLMS)/10 & Nonsignificant differences between groups \\
\hline & & Kim et al., $2012^{11}$ & $13 / 12$ & Nonsignificant differences between groups \\
\hline & $\begin{array}{l}{ }^{11} \mathrm{C} \text {-raclopride PET } \\
\text { (striatal } \mathrm{D}_{2} \text { receptors) }\end{array}$ & Turjanski et al., $1999^{13}$ & $13 / 14$ & $\begin{array}{l}\text { Decreased binding in the caudate }(p=0.01) \text { and putamen } \\
(p=0.008)\end{array}$ \\
\hline & $\begin{array}{l}{ }^{11} \mathrm{C} \text {-raclopride PET } \\
\text { (striatal } D_{2} \text { receptors) }\end{array}$ & Cervenka et al., $2006^{18}$ & $\begin{array}{l}16 \text { (not treated with } \\
\text { dopaminergic or opiate } \\
\text { agents) } / 16\end{array}$ & $\begin{array}{l}\text { Increased } \mathrm{DRD}_{2} \text { availability corresponding to higher } \mathrm{DRD}_{2} \\
\text { densities or lower levels of endogenous dopamine }\end{array}$ \\
\hline & $\begin{array}{l}{ }^{11} \mathrm{C} \text {-raclopride PET } \\
\text { (striatal } \mathrm{D}_{2} \text { receptors) }\end{array}$ & Oboshi et al., $2012^{19}$ & 8 (drug-naive)/8 & $\begin{array}{l}\text { Decreased } \mathrm{DRD}_{2} \text {-BP in the mesolimbic dopamine } \\
\text { region (nucleus accumbens) and caudate, and normal } \\
\text { in the putamen } \\
\text { Correlation between } \mathrm{DRD}_{2} \text {-BP and clinical severity } \\
\text { scores (negative) and with the degree of post-treatment } \\
\text { improvement with pramipexole (positive) in RLS patients }\end{array}$ \\
\hline & $\begin{array}{l}{ }^{11} \mathrm{C} \text {-raclopride } \mathrm{PET} \\
\text { (striatal } \mathrm{D}_{2} \text { receptors) }\end{array}$ & Earley et al., $2013^{20}$ & $31 / 36$ & $\begin{array}{l}\text { Decreased } \mathrm{DRD}_{2} \text {-BP in putamen and caudate, but not the } \\
\text { ventral striatum } \\
\text { DRD }_{2} \text {-BP did not differ between night and day for } \\
\text { either group } \\
\mathrm{DRD}_{2} \beta \text { (max) and } \mathrm{K}(\mathrm{d}) \text { did not differ significantly } \\
\text { between patients with RLS and control patients but did } \\
\text { show a strong and significant increase at night in the } \\
\text { ventral striatum } \\
\text { Lack of correlation of } \mathrm{DRD}_{2}-\mathrm{BP} \text { with any clinical measures } \\
\text { of RLS }\end{array}$ \\
\hline & $\begin{array}{l}{ }^{11} \mathrm{C} \text {-FLB PET (extrastriatal } \\
\mathrm{D}_{2} \text { receptors) }\end{array}$ & Cervenka et al., 2006 ${ }^{18}$ & $\begin{array}{l}16 \text { (not treated with } \\
\text { dopaminergic or opiate } \\
\text { agents)/16 }\end{array}$ & $\begin{array}{l}\text { Increased } \mathrm{DRD}_{2} \text { availability corresponding to higher } \\
\mathrm{DRD}_{2} \text { - densities or lower levels of endogenous dopamine }\end{array}$ \\
\hline $\begin{array}{l}\text { Serotonin } \\
\text { transporter (SERT) }\end{array}$ & ${ }^{123}$-beta-CIT-SPECT & Jhoo et al., $2010^{21}$ & 16 (drug-naive)/16 & $\begin{array}{l}\text { Nonsignificant differences between groups in the pons } \\
\text { and medulla } \\
\text { Negative correlation between the severity of RLS and the } \\
\text { availability of SERT }\end{array}$ \\
\hline Opioid receptor & ${ }^{11} \mathrm{C}$-diprenorphine PET & Von Spiczak et al., $2005^{22}$ & $15 / 12$ & $\begin{array}{l}\text { Nonsignificant differences between groups } \\
\text { Negative correlation between ligand binding and RLS } \\
\text { severity in the medial thalamus, amygdala, caudate } \\
\text { nucleus, anterior cingulate gyrus, insular cortex and } \\
\text { orbitofrontal cortex }\end{array}$ \\
\hline Regional blood flow & $\begin{array}{l}{ }^{18} \text { F-flurodeoxyglucose } \\
\text { PET }\end{array}$ & Trenkwalder et al., $1999^{12}$ & $6 / 10$ & Nonsignificant differences between groups \\
\hline
\end{tabular}

$C I T=2 \beta$-carbomethoxy-3 $\beta$-(4-iodophenyl)tropane; $D A=$ dopamine; $D A T=$ dopamine transporter; $D R D_{2}-B P=$ dopamine $D_{2}$ receptor binding potential; IPT = N-(3-iodopropen-2-yl)2beta-carbomethoxy-3beta-(chloro-phenyl) tropane; IBZM = (S)-2-hydroxy-3-iodo-6-methoxy-[(1-ethyl-2-pyrrolidinyl)methyl] benzamide; PET = positron emission tomography; SPECT = single photon emission computerised tomography. 
excitability and raise the possibility of a reduced $\mathrm{DRD}_{3}$ activation in the pathophysiology of RLS.

\section{Pharmacogenetic Studies Related to Dopaminergic Neurotransmission}

Desautels et al. ${ }^{36}$ found lack of relation between the risk of RLS and variations in eight genes coding for receptors and enzymes related to dopaminergic neurotransmission in a population of 92 patients having RLS and 182 controls $\left(D R D_{1^{\prime}} D R D_{2^{\prime}} D R D_{3^{\prime}} D R D_{4^{\prime}} D R D_{5^{\prime}}\right.$ dopamine transporter [DAT], TH and dopamine-beta-hydroxylase $[D B H])$. Our group confirmed the lack of relation between the main $D R D_{3}$ gene polymorphism and the risk of RLS in a study involving 206 RLS patients and 324 controls. ${ }^{37}$

\section{Iron Deficiency \\ Neuropathological Data}

Connor et al. ${ }^{3}$ found a marked decrease in iron-staining and $\mathrm{H}$-ferritin (heavy chain subunit of ferritin) staining in the substantia nigra, a mild decrease in transferrin receptor staining on neuromelanin-containing cells and morphological differences in the cells staining for L-ferritin (light chain subunit of ferritin) in seven iRLS brains compared with five control brains.

The same group found decreased concentrations of ferritin, divalent metal transporter 1 (DMT1), ferroportin and transferrin receptor, decreased activities of total iron regulatory proteins (IRP) and IRP1, decreased IRP1 protein levels, increased concentrations of transferrin and normal IRP2 protein levels in the neuromelanin cells of four iRLS patients compared with four controls..$^{38}$ These results were interpreted by the authors to suggest that RLS could arise from a defect in IRP1 in neuromelanin cells promoting destabilisation of the transferrin receptor mRNA, leading to cellular iron deficiency.

Wang et al. ${ }^{39}$ found the concentration of Thy 1 (an adhesion molecule that plays a role in the vesicular release of neurotransmitters) decreased to less than half in the substantia nigra of iRLS patients and also found a significant decrease of Thy1 in brain homogenates of adult rats exposed to an iron deficient (ID) diet compared with control adult rats, suggesting a relationship between Thy1 and iron in the pathogenesis of RLS and a possible mechanism by which iron deficiency compromises dopaminergic neurotransmission in RLS.

Snyder et al. ${ }^{40}$ described higher mitochondrial ferritin levels and higher cytochrome $\mathrm{C}$ staining (reflecting numbers of mitochondria) in the substantia nigra of eight iRLS patients than in eight controls, whereas these values were similar in the putamen, and iRLS patients showed decreased immunostaining for cytosolic $\mathrm{H}$-ferritin. The authors suggested that these alterations should contribute to insufficient cytosolic iron levels.

Connor et al. ${ }^{41}$ studied the expression of proteins related to iron management in the brain microvasculature and the epithelial cells of the choroids plexus in postmortem tissues and in 14 iRLS subjects and 18 healthy controls and found reduction of iron and $\mathrm{H}$-ferritin staining in the epithelial cells of choroids plexus and up-regulation of DMT1, ferroportin and transferrin and its receptor in IRLS patients. In the brain microvessels, they found decreased expression of $\mathrm{H}$-ferritin and transferrin and its receptor, as well as normality of DMT1, ferroportin, prohepcidin, mitochondrial ferritin and L-ferritin in IRLS patients. These data provided some evidence that brain microvessels and blood-brain barrier have a role in the regulation of iron uptake and storage.

\section{Transcranial Sonography}

Several studies found hypoechogenicity of the substantia nigra (related to local iron deposition), though less marked than in idiopathic Parkinson's disease ${ }^{42-44}$ and in brainstem raphe ${ }^{44}$ and hyperechogenicity of the red nucleus ${ }^{44}$ of patients having RLS.

\section{Neuroimaging Studies}

Allen et al. ${ }^{45}$ found a significant decrease of iron in an R2' magnetic resonance imaging (MRI) sequence in the substantia nigra and, to a lesser degree, in the putamen of five iRLS patients compared with five controls.

Earley et al. ${ }^{46}$ studied the iron concentration or "iron index" in 10 brain regions using MRI in 22 early-onset iRLS patients, 19 late-onset iRLS patients and 39 controls. They found that the mean iron index from the substantia nigra was significantly lower in early-onset RLS than in controls, whereas this value was similar in late-onset RLS and in controls. The severity of RLS was negatively correlated with the iron index in the substantia nigra of early-onset RLS patients. By contrast, Moon et al. ${ }^{47}$ in a similarly designed study involving 20 early-onset iRLS patients, 17 late-onset iRLS patients and 40 healthy controls, found the mean iron index from the substantia nigra significantly lower in lateonset RLS than in controls but similar in early-onset RLS and in controls.

Godau et al. ${ }^{48}$ found mean T2 values in MRI slightly higher in several brain areas of six iRLS patients than in those of controls, and these values correlated inversely with substantia nigra echogenicity.

Knake et al. ${ }^{49}$ using a T2* gradient MRI sequence in 12 regions of interest, reported nonsignificant differences in 12 iRLS patients and 12 controls.

Rizzo et al., ${ }^{50}$ using a MRI phase imaging in 15 iRLS patients and 15 controls, found significantly higher values (indicating reduced iron content) in the substantia nigra, thalamus, putamen and pallidum.

\section{Cerebrospinal Fluid, Plasma/Serum and Lymphocyte Studies of Iron, Ferritin and Transferrin Levels}

Table 2 summarises the results of case-control studies on CSF and plasma/serum levels of iron, ferritin and its subunits and transferrin. These studies are scarce and their results variable.

CSF iron levels were found to be similar in IRLS patients and controls. ${ }^{51,52}$ However, plasma iron has been found to be similar in iRLS and controls in two studies ${ }^{51,55}$ and decreased by $50 \%$ in iRLS patients in other. ${ }^{52}$ CSF transferrin levels have been reported normal ${ }^{51,52}$ or increased, ${ }^{53}$ and plasma/ serum transferrin levels have been reported normal ${ }^{51,55}$ or increased ${ }^{52}$ as well.

With regard to ferritin, serum/plasma levels were found normal in two studies $^{5,53}$ and decreased in two others, ${ }^{53,56}$ and two studies showed an inverse correlation between plasma/serum ferritin and RLS severity. ${ }^{55,56}$ Although one study described normal CSF ferritin levels in a short series of iRLS and controls, ${ }^{52}$ another group described lower CSF ferritin in iRLS patients, ${ }^{53}$ at least in those patients having early onset of symptoms ${ }^{51}$ and those having high CSF 3-OMD levels. ${ }^{27}$

Early et al. ${ }^{51}$ reported significantly lower CSF ferritin (by $50 \%$; $p<0.001$ ), and significantly higher CSF transferrin (by fivefold; $p<0.001$ ) in RLS patients, but not controls, when comparing CSF samples obtained at 
Table 2: Alterations in the CSF Levels of Iron, Ferritin and Transferrin in Patients with Idiopathic Restless Legs Syndrome Compared with Controls

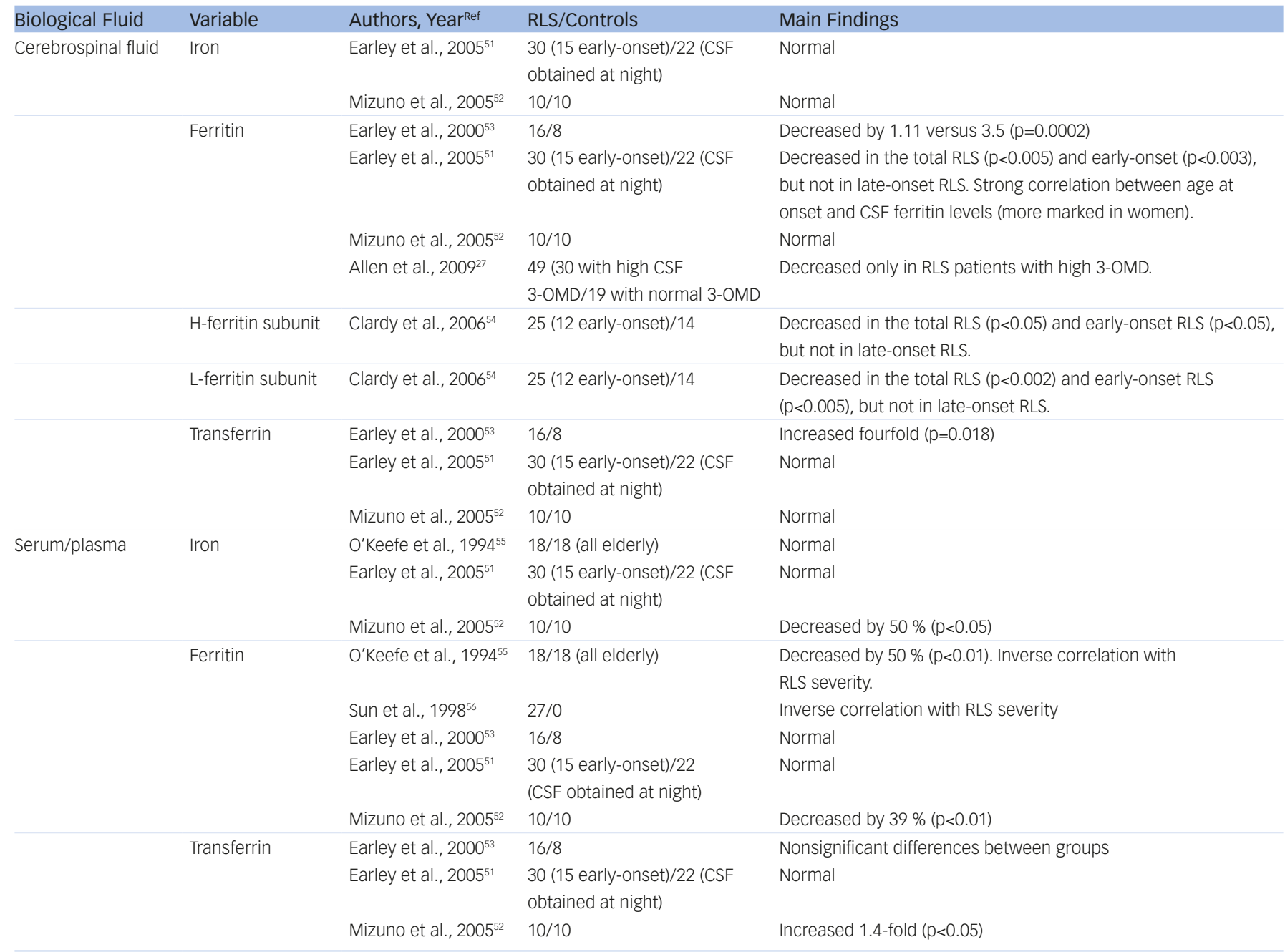

3-OMD = 3-orthomethyl-DOPA; CSF = cerebrospinal fluid .

10 a.m. with those obtained at 10 p.m., suggesting a circadian rhythm. Iron levels were similar in 10 a.m. and 10 p.m. samples in both groups. These results imply that the hour of sample collection can be very important to results and cause variability among studies.

A cross-sectional study of 365 elderly German subjects, with an RLS prevalence of $9.8 \%$, in whom iron, ferritin, transferrin, soluble transferrin receptor and $\mathrm{C}$-reactive protein were measured in plasma, failed to find evidence that iron or ferritin deficiency should be a major cause of iRLS in the sample. ${ }^{57}$ In a population-based study in Iceland and Sweden with a prevalence of RLS of $18.3 \%$ in Icelandic and $11.5 \%$ in Swedish, ferritin levels were significantly lower in RLS subjects ( $p=0.0002$ ), but the statistical significance disappeared after adjustment for centre, age, sex and smoking history. ${ }^{58}$

Finally, a report by Earley et al., ${ }^{59}$ which involved 24 early-onset RLS patients and 25 controls (all women), found increased levels of transferrin receptor and DMT1 protein, as well as normal ferritin subtypes and transferrin levels, in the lymphocytes of iRLS patients.

\section{Experimental Data}

ID diet can induce RLS-like sensory and motor symptoms in rodents, reduces the acute pain threshold, increases the chronic pain response (similarly to RLS patients) and shows an elevated expression of C-Fos immunoreactive cells in the ipsilateral dorsal horns. ${ }^{60}$ Several data suggest an important interaction between ID and the dopaminergic system in the pathogenesis of RLS:

(a) RLS-like symptoms induced by ID diet are more marked in $\mathrm{DRD}_{3}$ knockout than in wild mice. ${ }^{61}$

(b) As already mentioned, ID increases locomotor activities in mice lesioned bilaterally with 6-OHDA in the A11 nuclei, this effect being reversed by the $\mathrm{DRD}_{2} / \mathrm{DRD}_{3}$ agonists ropinirole ${ }^{32,33}$ and pramipexole. ${ }^{34}$

(c) ID decreases DAT density in the light (by $20 \%$ ) and dark (by $28 \%$ ) phases and increases the DOPAC/DA ratio the extracellular fluid of mice in the dark phase only. ${ }^{62}$

(d) ID decreases DAT mRNA (by $58 \%$ ), DAT protein and membrane associated (suggesting alterations in dopamine uptake) and increases the noradrenalin concentration in the caudate of rats and makes the response of DA levodopa $50 \%$ smaller and delayed and the response of noradrenalin to levodopa threefold higher in this model, suggesting compensatory changes in noradrenalin metabolism.63

(e) ID induces increased extracellular striatal DA, reduces intracellular striatal DA and striatal DA uptake and blunts DRD $_{2}$ agonist feedback enhancement of striatal uptake in the ventral midbrain of rodents. 
Increase in extracellular striatal DA and decrease in intracellular striatal DA, induced by ID, are reversed by the infusion of physiological concentrations of iron into the ventral midbrain, whereas the remaining variables were unchanged. ${ }^{64}$

(f) ID induces changes of expression of several genes in the substantia nigra of rodents: $D R D_{2}$, stromal cell-derived factor 1 ( $C x C / 12$ or $S D F-1$; a ferritin regulator and potent dopamine neuromodulator) and haemoglobin beta adult chain 1, or Hbb-b1 (which plays some functional role in dopaminergic neurons). ${ }^{65}$

(g) ID induces increased density of striatal adenosine A2A receptor (closely related to dopaminergic signalling) in rodents. In this model, selective A2A receptor antagonists blocked both effects mediated by striatal presynaptic A2A (motor output induced by cortical electric stimulation) and postsynaptic A2A receptors (ERK phosphorylation induced by cortical electrical stimulation as well). These results were interpreted as an indicative of a functional upregulation of striatal $\mathrm{A} 2 \mathrm{~A}$ receptors (both pre- and postsynaptic) induced by brain iron deficiency, which could be extrapolated to RLS as a model of a sensory motor disorder associated with iron deficiency.66

\section{Serotonergic System}

Earley et al. ${ }^{23}$ described similar CSF levels of 5-HIAA (the main metabolite of serotonin or $5-\mathrm{HT}$ ) in $16 \mathrm{iRLS}$ patients (samples obtained at 10 a.m.) to those in 14 healthy controls (not age-matched), but this value was lower when adjusted for age. In a further study, they found similar CSF 5-HIAA levels in RLS patients and controls, but higher CSF HVA/5-HIAA ratio in samples obtained at 10 p.m. than in those of their previous study with samples obtained at 10 a.m., suggesting changes related to the circadian rhythm, as already described. ${ }^{24}$ However, Poceta et al. ${ }^{26}$ found no evidence of a significant circadian rhythm for CSF 5-HIAA in a study obtaining samples every 30 minutes during 22 hours in three iRLS patients and three controls.

Stiasny-Kolster et al. ${ }^{25}$ found similar CSF 5-HIAA levels in 22 drug-naive RLS patients and 11 healthy controls.

Jhoo et al. ${ }^{21}$ found nonsignificant differences in the binding of serotonin transporter (SERT) in the pons and medulla in 16 iRLS patients and 16 controls but reported a negative correlation between the severity of RLS and the availability of SERT (see Table 1).

\section{Aspartate, Glutamatergic and Gabaergic Systems}

The possible role of gamma-aminobutyric acid (GABA) in the pathophysiology or iRLS is suggested by the improvement of RLS symptoms with GABAergic drugs, mainly gabapentin (used as secondline therapy) and pregabalin. Two recent studies suggested a relationship between excitotoxic (aspartate and glutamate) and inhibitory (GABA) amino acid neurotransmitters and iRLS:

(a) Rizzo et al., ${ }^{67}$ in a study involving 23 iRLS patients and 19 controls using proton MR spectroscopy ('HMRS), found a reduction in $\mathrm{N}$-acetylaspartate (NAA) concentrations and in NAA:creatine ratio in the medial thalamus of iRLS patients ( $p<0.01$ for both), as well as an association of lower NAA levels with a family history of iRLS.

(b) Allen et al.,68 in a study with "HMRS involving 28 iRLS patients and 20 controls, found higher thalamic glutamate+ glutamine/creatine ratios in RLS patients, correlated with several RLS-related polysomnographic sleep variables (including the wake time during sleep), with the exception of periodic movements during sleep per hour.

(c) Winkelman et al., ${ }^{69}$ in a study with 'HMRS involving 18 iRLS patients and 17 controls, found similar levels of GABA, glutamate and NAA in the thalamus and cerebellum in both study groups, higher levels of NAA in the dorsal anterior cingulate cortex of RLS patients and similar levels of GABA and glutamate in this region. They also found that thalamic GABA levels showed a positive correlation with periodic limb movement indices and RLS severity and that cerebellar GABA levels negatively correlated with these parameters.

Our group found lack of association between the rs3794987 single nucleotide polymorphism (the most frequent or the solute carrier family 1, member 2, or SLC1A2 gene, related to the transport of glutamate) with risk of iRLS (205 iRLS patients and 328 controls). ${ }^{70}$

\section{Opiate System}

Even though opioids are an effective treatment used as third-line therapy for iRLS, there are only few reports about the possible role of opiate system in its pathogenesis. A neuropathological study involving five females having iRLS and six healthy controls (five of them females) showed a significant reduction of beta-endorphin and met-enkephalin cells in, as well as similar leu-enkephalin cells in the thalamus of iRLS patients compared with controls, whereas beta-endorphin, metenkephalin, leu-enkephalin and TH cells were similar in the substantia nigra of both study groups. ${ }^{4}$

A functional study with "diprenorphine PET (a marker of opiate receptor) found no significant differences of binding between IRLS patients and controls, though a negative correlation between ligand binding to several brain areas and RLS severity was described.22

Finally, pre-administration of a delta-opioid peptide prevented neuronal damage induced by iron deficiency in cell cultures of substantia nigra of rats. ${ }^{11}$

\section{Hypocretin-1 (Orexin-A)}

Allen et al. ${ }^{72}$ found increased CSF levels of hypocretin-1 (a wellestablished marker of narcolepsy) in evening samples from patients having iRLS (especially in patients having early-onset RLS) in a study involving 16 RLS patients (nine of them having early-onset iRLS) and eight controls. This finding was not confirmed by Stiasny-Kolster et al. ${ }^{73}$ in a study involving 13 iRLS patients (seven of them having earlyonset RLS) and nine controls, and this group did not find correlation of CSF hypocretin-1 levels with age at onset or severity of RLS. Mignot et al. ${ }^{74}$ studied CSF hypocretin-1 levels in 274 subjects having various sleep disorders, 10 of them having RLS, but found similar levels in this subgroup of patients in comparison with 64 healthy controls and 228 controls having other neurological diseases. Finally, Poceta et al. ${ }^{26}$ found no evidence of a significant circadian rhythm for CSF hyprocretin-1 in a study obtaining samples every 60 minutes during 22 hours in three iRLS patients and three controls.

\section{Vitamin D Deficiency}

Several recent works have called attention to the possible role of vitamin D deficiency in the aetiology of iRLS. This is a new interesting observation, for depletion of 25-hydroxyvitamin D may lead to dopaminergic dysfunction.

Balaban et al. ${ }^{75}$ found a significant decrease of serum 25-hydroxyvitamin D levels (by $40 \%, p<0.001$ ) in females having iRLS compared with 
female controls, as well as an inverse correlation between this value and disease severity in females in a study involving 36 iRLS patients and 38 healthy controls.

Oran et al. ${ }^{76}$ measured serum 25-hydroxyvitamin D levels in 155 patients having musculoskeletal symptoms and found a significantly higher prevalence of iRLS in the 119 patients with serum 25-hydroxyvitamin D levels $<20 \mathrm{ng} / \mathrm{ml}$ than in the 36 with this value $>20 \mathrm{ng} / \mathrm{ml}(p<0.001)$.

The results of a proteomic analysis of CSF in five early-onset RLS patients and five controls identified an increase of CSF vitamin D binding protein levels as a possible biomarker for RLS, together with increase of CSF cystatin C, lipocalin-type prostaglandin D2 synthase and betahemoglobin, as well as decrease of apolipoprotein A2 and alpha-1-acid glycoprotein levels. ${ }^{77}$

\section{Nitric Oxide}

Baskol et al. ${ }^{78}$ described increased plasma levels of advanced oxidation protein products, increased serum levels of malondialdehyde (MDA, a marker of lipid peroxidation), and decreased serum levels of thiol (an antioxidant molecule) and nitrites (a marker of NO) in 22 iRLS patients compared with 20 age- and gender-matched controls. The expression of NO synthase 1 (NOS1, neuronal NOS or nNOS) and nitrotyrosine have been found increased in the substantia nigra of four out of six iRLS patients and in none of six controls in a immunohistochemical study. ${ }^{79}$ Finally, Clemens et al. ${ }^{80}$ found increased NOS expression in the thoracic intermediolateral nucleus of the spinal cord of dopamine D3 receptor knockout mice compared with wild mice. These data suggest a possible role of $\mathrm{NO}$ and oxidative stress in the pathophysiology of iRLS.

Though a three-stage design study including an explorative casecontrol study (367 cases and 367 controls, screening 1,536 SNPs in 366 genes), a replication case-control study (551 cases and 551 controls) and a fine mapping study of 34 tagging SNPs in both samples combined found association between the SNPS rs7977109 and rs693534 and the risk of RLS (only rs7977109 remained as significant after testing for multiple comparisons), ${ }^{81}$ a replication study by our group of 205 iRLS patients and 328 controls failed to find this association. ${ }^{82}$

\section{Other Substances}

Wetter et al. ${ }^{83}$ found similar plasma levels of prolactin, growth hormone and cortisol in 10 RLS patients and eight controls and reported that both groups showed the same rhythms during the night and day for all hormones. By contrast, Schilling et al. ${ }^{84}$ reported increased nocturnal urinary cortisol excretion in 73 iRLS patients compared with 34 matched controls.

Tribl et al. ${ }^{85}$ found similar day and night urinary excretion of 6-hydroxymelatonin-sulfate in 15 iRLS patients and 11 controls.

when administered centrally in rats, alpha-melanocyte stimulating hormone (alpha-MSH) and adrenocorticotropic hormone (ACTH) stimulate motor activity when awake, cause changes in sleep architecture and increase periodic movement in sleep, suggesting that they may play a role in the pathogenesis of RLS. ${ }^{86}$

Plasma levels of folate, ${ }^{55,87}$ vitamin $\mathrm{B}_{12,}{ }^{55,87}$ vitamin $\mathrm{B}_{6^{\prime}}{ }^{87}$ homocysteine ${ }^{87}$ and CSF, as well as plasma levels of magnesium ${ }^{88}$ have been found similar in IRLS patients and controls.

\section{Grey Matter and White Matter Density Studies Grey Matter}

Several studies assessed grey matter density or volume using voxel-based morphometry (VBM) with MRI in iRLS patients. Hornyak et al., ${ }^{89}$ in a study involving 14 untreated IRLS patients and 14 matched controls, showed slightly increased grey matter density in the ventral hippocampus and in the middle orbitofrontal gyrus. Pan et al..$^{90}$ found a significant reduction in the grey matter density of 16 drug-naive iRLS patients having depressive symptoms, in comparison with 18 drug-naive IRLS patients without depression symptoms and with 18 healthy controls, but they did not find significant differences of grey matter density when comparing the whole group or iRLS patients or the nondepressed RLS patients with the control group.

Chang et al. ${ }^{91}$ described regional decreases of grey matter volume in several areas of iRLS patients, including the left hippocampal gyrus, both parietal lobes, the medial frontal areas and cerebellum.

By contrast, Comley et al. ${ }^{92}$ found no significant differences in grey matter density in 16 drug-naive iRLS and 16 controls, and Rizzo et al. ${ }^{67}$ found no significant differences in the medial thalamus in a study involving 23 iRLS patients and 19 controls.

\section{White Matter}

Unrath et al., ${ }^{93}$ using diffusion tensor imaging in 45 iRLS patients and 30 controls, found reduced fractional anisotropy (FA, a marker of white matter integrity) in multiple subcortical areas in close proximity to the primary and associated motor and somatosensitive areas, in the posterior ventral lateral nucleus of the right thalamus), in motor projectional fibres and in the proximity of the left anterior cingulum. According with the authors, these findings supported alterations in the subcortical network involving cerebral sensorimotor pathways. In contrast, Rizzo et al. ${ }^{67}$ found no significant differences in the medial thalamus in a study involving 23 iRLS patients and 19 controls.

Finally, Connor et al. ${ }^{94}$ described decreased expression (by approximately $25 \%$ ) of myelin basic protein, proteolipid protein and the olygodendrocyte-specific 3'5'-cyclic nucleotide phosphohydrolase, along with decreased amounts of transferrin and $\mathrm{H}$-ferritin, in the myelin of 11 iRLS patients compared with that of 11 controls in a neuropathological study. They also reported significant small decreases in white matter volume in 23 RLS patients compared with 23 controls in the corpus callosum, anterior cingulum and precentral gyrus.

\section{Transcranial Magnetic Stimulation Studies}

A noninvasive neurophysiological technique used to assess the excitability of the primary motor cortex and the cortical-spinal tract, transcranial magnetic stimulation (TMS), has been the matter of several studies in patients having iRLS (reviewed in reference 96). The findings reported in patients having iRLS compared with controls include:

\section{Single-pulse Transcranial Magnetic Stimulation Variables Motor-evoked Potentials}

Motor-evoked potentials (MEPS) recorded in the contralateral target muscles have been found normal, suggesting integrity of the corticalspinal pathway. ${ }^{97-103}$

\section{Resting Motor Threshold}

Resting motor threshold (rMT) - that is, the minimum stimulus intensity required to obtain a MEP having a minimum of amplitude in five or more 
of 10 consecutive stimuli at best-has been reported normal by most studies, ${ }^{98-108}$ with the exception of one that reported increased active rMT in the tibialis anterioris muscle ${ }^{97}$ and another that observed decreased active rMT from the first dorsal interosseous, but only at night. ${ }^{109}$ rMT is increased in situations of damage of the cortical-spinal tract and decreased in situations of hyperexcitability of the cortical-spinal system. The normality of values found in most studies suggests integrity of the cortical-spinal pathway as well.

\section{Cortical Silent Period}

Cortical silent period (CSP), suppression of the electromyographic activity that follows the MEP when a single magnetic pulse is delivered during a voluntary contraction of the contralateral muscle (indicating suppression of the cortical-spinal system), has been found markedly shortened in many studies, $97-99,102,105,107$ this effect being reversed by dopaminergic drugs. ${ }^{97,101,107}$ By contrast, other studies found it normal. $.9,100,103,104,109,110$

\section{Paired-pulse Transcranial Magnetic Stimulation Variables Short-latency Intracortical Inhibition}

Short-latency intracortical inhibition (SICl), likely reflecting the excitability of GABA-ergic inhibitory cortical neurons, has been found markedly reduced in patients with iRLS, especially in the most affected side, ${ }^{98-100,102-}$ $104,108,111$ this effect being reversed with dopaminergic therapy. ${ }^{100,102,108}$

\section{Intracortical Facilitation}

Intracortical facilitation (ICF), likely related to the activity of intracortical glutamatergic excitatory circuits, has been found normal in three studies, ${ }^{100,103,108}$ whereas two others showed hyperfacilitation in iRLS. ${ }^{98,104}$

\section{Transcranial Magnetic Stimulation Measures of Sensorimotor Variables Short-latency Afferent Inhibition}

Short-latency afferent inhibition (SAI), or suppression of the amplitude of MEP induced by an electrical stimulus applied to the median nerve at the wrist $20 \mathrm{~ms}$ before TMS of the hand area of the contralateral motor cortex (a probable reflection of the integrity of cholinergic neural circuits), has been found reduced in IRLS, with reversion after dopaminergic therapy, in a single study. ${ }^{108}$

\section{Long-latency Afferent Inhibition}

Long-latency afferent inhibition (LAl), probably related to corticalcortical connections involving the motor cortex and primary and secondary somatosensory cortical areas, has been reported normal. ${ }^{108}$

\section{Plasticity-related Transcranial Magnetic Stimulation Measures}

Postexercise facilitation in response to TMS has been found decreased in untreated iRLS patients, 99,102,111 and dopamine agonists can reverse delayed facilitation. ${ }^{102}$

\section{Conclusions and Future Approaches}

To date, the main support for the possible role of dopaminergic dysfunction in IRLS is the therapeutic response to dopaminergic drugs and data obtained from the two proposed experimental models of RLS (stereotactic lesions with 6-OHDA into $\mathrm{A} 11$ area and $\mathrm{DRD}_{3}$ knockout mice), with or without the contribution of ID, as previously discussed. Neuropathological studies on this matter are scarce and performed in only a limited number of patients, though some have found changes suggesting dopaminergic dysfunction and its relationship with iron insufficiency. ${ }^{5}$ The results of functional studies of the dopaminergic function (see Table 1) are controversial, for only some of them showed a mild involvement of presynaptic dopaminergic terminal, and involvement of $\mathrm{DRD}_{2}$ has been shown in studies using ${ }^{11} \mathrm{C}$-raclopride, but not in studies using IBZM as the tracer. Interestingly, studies having larger samples sizes suggested decreased DAT binding in both day and night scans ${ }^{15}$ and found decreased $D R D_{2}$ binding potentials in the striatum..$^{20}$ The results of studies on CSF DA metabolites are based on studies having low sample sizes and are also controversial. The possible relationship of CSF 3-OMD levels with CSF HVA levels and RLS severity ${ }^{27}$ and the possibility of a circadian rhythm for CSF DA and HVA concentrations ${ }^{24,26}$ are potentially interesting findings deserving confirmation.

Regarding a possible role for iron deficiency in the pathogenesis of iRLS, neuropathological (although based in small size series), neuroimaging and transcranial sonographic studies point at this hypothesis. Moreover, RLS could be induced in experimental animals with ID diet, and there are important interactions between ID and the dopaminergic system in these models, as already mentioned. However, the results of CSF and serum or plasma levels of iron, ferritin and transferrin are controversial and are based on small samples. In this regard, the finding by Early et al..$^{51}$ of the variability of CSF ferritin and transferrin levels depending on the hour of the sample collection is of special interest.

Together with studies assessing the role of dopaminergic dysfunction and iron deficiency as the main pathogenical hypothesis of $\mathrm{IRLS}$, recent studies have explored the possible implication of other neurotransmitters or neuromodulators, such as serotonin, aspartate, glutamate, GABA and opiates; the role of oxidative stress and NO; and the possibility of vitamin D deficiency in the pathogenesis of this disease. However, the results of these studies should be considered preliminary and deserving of further confirmation.

Why iRLS exclusively or predominantly affects the lower limbs is not well understood, though we could speculate that nigrostriatal dopaminergic dysfunction should affect somatotopic projections of the lower limbs at the putamen or a possible selective alteration of the projections of the diencephalic-spinal system to lower limbs.

Ideally, futures studies trying to establish the pathogenic mechanisms of RLS should include the following:

(a) A multicentre and prospective design, with a long-term follow-up of patients.

(b) Inclusion of patients diagnosed as having IRLS according to standardised criteria' and who have family history of RLS, regardless of the duration of the disease.

(c) Periodic clinical evaluations of patients, including through the International RLS Group Rating Scale (IRLSGRS). ${ }^{95}$

(d) Periodic study of patients using MRI, transcranial ultrasonography, DAT-SPECT and IBZM or ${ }^{11} \mathrm{C}$ raclopride PET during the follow-up period.

(e) Serial CSF and plasma or serum sample collection at different hours, as in the study by Poceta et al., ${ }^{26}$ before starting treatment; measurement of multiple potential biological markers in the CSF is desirable.

(f) Patient blood DNA collection for genetic studies related to potential biomarkers.

(g) Neuropathological examination of the brain of patients who die during the study interval. 
1. Allen RP, Picchietti D, Hening WA, et al., Restless legs syndrome: diagnostic criteria, special considerations, and epidemiology - a report from the Restless Legs syndrome Diagnosis and Epidemiology Workshop at the National Institute of Health, Sleep Med, 2003:4:101-19.

2. Allen RP Picchietti DL, Garcia-Borreguero D, et al, International Restless Legs Syndrome Study Group, Restless legs syndrome/Willis-Ekbom disease diagnostic criteria: updated International Restless Legs Syndrome Study Group (IRLSSG) consensus criteria-history, rationale, description, and significance. Sleep Med, 2014;15:860-73.

3. Connor JR, Boyer PJ, Menzies SL, et al., Neuropathological examination suggests impaired brain iron acquisition in restless legs syndrome, Neurology, 2003;61:304-9.

4. Walters AS, Ondo WG, Zhu W, et al., Does the endogenous opiate system play a role in the Restless Legs Syndrome? A pilot post-mortem study, J Neurol Sci, 2009;279:62-5.

5. Connor JR, Wang XS, Allen RP, et al., Altered dopaminergic profile in the putamen and substantia nigra in restless legs syndrome, Brain, 2009;132:2403-12.

6. Earley CJ, Allen RP, Connor JR, et al., The dopaminergic neurons of the A11 system in RLS autopsy brains appea normal, Sleep Med, 2009:10:1155-7.

7. Eisensehr I, Wetter TC, Linke R, et al., Normal IPT and IBZM SPECT in drug-naive and levodopa-treated idiopathic restless legs syndrome, Neurology, 2001;57:1307-9.

8. Linke R, Eisensehr I, Wetter TC, et al., Presynaptic dopaminergic function in patients with restless legs syndrome: are there common features with early Parkinson's disease? Mov Disord, 2004;19:1158-62

9. Michaud M, Soucy JP, Chabli A, et al., SPECT imaging of striatal pre- and postsynaptic dopaminergic status in restless legs syndrome with periodic leg movements in sleep, J Neurol, 2002;249:164-70.

10. Mrowka M, Jöbges M, Berding G, et al., Computerized movement analysis and beta-CIT-SPECT in patients with restless legs syndrome, I Neural Transm, 2005; 112:693-701

11. Kim KW, Jhoo JH, Lee SB, et al., Increased striatal dopamine transporter density in moderately severe old restless legs syndrome patients. Eur I Neurol, 2012:19:1213-8.

12. Trenkwalder $C$, Walters AS, Hening WA, et al., Positron emission tomographic studies in restless legs syndrome Mov Disord, 1999:14:141-5.

13. Turjanski N, Lees AJ, Brooks DJ, Striatal dopaminergic function in restless legs syndrome: 18F-dopa and 11C-raclopride PET studies, Neurology, 1999;52:932-7.

14. Ruottinen HM, Partinen M, Hublin C, et al., An FDOPA PET study in patients with periodic limb movement disorder and restless legs syndrome, Neurology, 2000;54:502-4.

15. Earley CJ, Kuwabara H, Wong DF, et al., The dopamine transporter is decreased in the striatum of subjects with restless legs syndrome, Sleep, 2011;34:341-7.

16. Tribl GG, Asenbaum S, Klösch G, et al., Normal IPT and IBZM SPECT in drug naive and levodopa-treated idiopathic restless legs syndrome, Neurology, 2002;59:649-50

17. Tribl $G G$, Asenbaum $S$, Happe $S$, et al., Normal striatal D2 receptor binding in idiopathic restless legs syndrome with periodic leg movements in sleep, Nucl Med Commun, 2004;25:55-60.

18. Cervenka S, Pålhagen SE, Comley RA, et al., Support for dopaminergic hypoactivity in restless legs syndrome: a PET study on D2-receptor binding, Brain, 2006;129:2017-28

9. Oboshi Y, Ouchi Y, Yagi S, et al., In vivo mesolimbic D2/3 receptor binding predicts posttherapeutic clinical responses in restless legs syndrome: a positron emission tomography study, I Cereb Blood Flow Metab, 2012;32:654-62.

20. Earley CJ, Kuwabara H, Wong DF, et al., Increased synaptic dopamine in the putamen in restless legs syndrome, Sleep 2013;36:51-7.

21. Jhoo $\mathrm{JH}$, Yoon IY, Kim YK, et al., Availability of brain serotonin transporters in patients with restless legs syndrome. Neurology, 2010;74:513-8

22. von Spiczak $S$, Whone AL, Hammers $A$, et al. The role of opioids in restless legs syndrome: an [11C]diprenorphine PET study, Brain, 2005:128:906-17.

23. Earley CJ, Hyland K, Allen RP, CSF dopamine, serotonin, and biopterin metabolites in patients with restless legs syndrome Mov Disord, 2001:16:144-9.

24. Earley CJ, Hyland K, Allen RP, Circadian changes in CSF dopaminergic measures in restless legs syndrome, Sleep Med, 2006; 7:263-8.

25. Stiasny-Kolster K, Möller JC, Zschocke J, et al., Normal dopaminergic and serotonergic metabolites in cerebrospinal fluid and blood of restless legs syndrome patients, Mov Disord, 2004;19:192-6.

26. Poceta JS, Parsons L, Engelland S, et al., Circadian rhythm of CSF monoamines and hypocretin-1 in restless legs syndrome and Parkinson's disease, Sleep Med, 2009:10: 129-33.

27. Allen RP, Connor JR, Hyland K, et al., Abnormally increased CSF 3-Ortho-methyldopa (3-OMD) in untreated restless legs syndrome (RLS) patients indicates more severe disease and possibly abnormally increased dopamine synthesis, sleep Med, 2009:10:123-8.

28. Qu S, Ondo WG, Zhang $X$, et al., Projections of diencephalic dopamine neurons into the spinal cord in mice, Exp Brain Res, 2006;168:152-6.

29. Barraud Q, Obeid I, Aubert I, et al., Neuroanatomical study of the A11 diencephalospinal pathway in the non-human primate, PLOS One, 2010;5:e13306.

30. Pappas SS, Behrouz B, Janis KL, et al., Lack of D2 receptor mediated regulation of dopamine synthesis in A11 diencephalospinal neurons in male and female mice, Brain

31. Ondo WG, He Y, Rajasekaran $S$, et al., Clinical correlates of 6-hydroxydopamine injections into A11 dopaminergic neurons in rats: a possible model for restless legs syndrome Mov Disord, 2000:15:154-8.

32. Zhao H, Zhu W, Pan T, et al., Spinal cord dopamine receptor expression and function in mice with 6-OHDA lesion of th A11 nucleus and dietary iron deprivation, J Neurosci Res, 2007;85:1065-76

33. Qu S, Le W, Zhang X, et al., Locomotion is increased in a11-lesioned mice with iron deprivation: a possible animal model for restless legs syndrome, I Neuropathol Exp Neurol, 2007;66:383-8

34. Luo F, Li C, Ondo WG, et al., The long-term effects of the dopamine agonist pramipexole in a proposed restless legs syndrome animal model, Sleep Med, 2011;12:41-6.

35. Clemens S, Hochman S, Conversion of the modulatory actions of dopamine on spinal reflexes from depression to facilitation in D3 receptor knockout mice, J Neurosci, 2004:24:11337-45.

36. Desautels A, Turecki G, Montplaisir J, et al., Dopaminergic neurotransmission and restless legs syndrome: a genetic association analysis, Neurology, 2001:57:1304-6.

37. Jiménez-Jiménez FJ, Alonso-Navarro H, Martínez C, et al., Dopamine Receptor D3 (DRD3) gene rs6280 variant and risk for restless legs syndrome, Sleep Med, 2013; 14:382-4.

38. Connor JR, Wang XS, Patton SM, et al., Decreased transferrin receptor expression by neuromelanin cells in restless legs syndrome, Neurology, 2004;62:1563-7.

39. Wang $X$, Wiesinger J, Beard J, et al., Thy1 expression in the brain is affected by iron and is decreased in Restless Legs Syndrome, J Neurol Sci, 2004;220:59-66.

40. Snyder AM, Wang X, Patton SM, et al., Mitochondrial ferritin in the substantia nigra in restless legs syndrome, J Neuropatho Exp Neurol, 2009:68:1193-9.

41. Connor JR, Ponnuru P, Wang XS, et al., Profile of altered brain iron acquisition in restless legs syndrome, Brain, 2011:134:959-68.

42. Ryu JH, Lee MS, Baik JS, Sonographic abnormalities in idiopathic restless legs syndrome (RLS) and RLS in Parkinson's disease, Parkinsonism Relat Disord, 2011; 17: 201-3.

43. Godau J, Manz A, Wevers AK, et al., Sonographic substantia nigra hypoechogenicity in polyneuropathy and restless legs syndrome, Mov Disord, 2009;24:133-7.

44. Godau J, Wevers AK, Gaenslen A, et al., Sonographic abnormalities of brainstem structures in restless legs syndrome, Sleep Med, 2008:9:782-9.

45. Allen RP, Barker PB, Wehrl F, et al., MRI measurement of brain iron in patients with restless legs syndrome, Neurology, 2001:56:263-5

46. Earley CJ, Barker PB, Horská A, et al., MRI-determined regional brain iron concentrations in early-and late-onset restless legs syndrome Sleep Med, 2006;7:458-61.

47. Moon HJ, Chang Y, Lee YS, et al., T2 relaxometry using 3.0-tesla magnetic resonance imaging of the brain in early- and late-onset restless legs syndrome, J Clin Neurol, 2014;10:197-202

48. Godau J, Klose U, Di Santo A, et al., Multiregional brain iron deficiency in restless legs syndrome, Mov Disord, 2008;23:1184-7.

49. Knake S, Heverhagen JT, Menzler K, et al., Normal regiona brain iron concentration in restless legs syndrome measure by MRI, Nat Sci Sleep, 2009:2:19-22.

50. Rizzo G, Manners D, Testa C, et al., Low brain iron content in idiopathic restless legs syndrome patients detected by phase imaging, Mov Disord, 2013;28:1886-90.

51. Earley CJ, Connor JR, Beard JL, et al., Ferritin levels in the cerebrospinal fluid and restless legs syndrome: effects of different clinical phenotypes, Sleep, 2005: 28: 1069-75.

52 Mizuno S, Mihara T Miyaoka T et al, CSF iron ferritin and transferrin levels in restless legs syndrome, $J$ Sleep Res, 2005:14:43-7.

53. Earley CJ, Connor JR, Beard JL, et al., Abnormalities in CSF concentrations of ferritin and transferrin in restless legs syndrome, Neurology, 2000;54:1698-700

54. Clardy SL, Earley CJ, Allen RP, et al., Ferritin subunits in CSF are decreased in restless legs syndrome, I Lab Clin Med, 2006;147:67-73.

55. O'Keeffe ST, Gavin K, Lavan JN, Iron status and restless legs syndrome in the elderly, Age Ageing, 1994;23:200-3

56. Sun $\mathrm{ER}$, Chen $\mathrm{CA}$, $\mathrm{Ho} \mathrm{G}$, et al., Iron and the restless legs syndrome, Sleep, 1998;21:371-7.

57. Berger $\mathrm{K}$, von Eckardstein $\mathrm{A}$, Trenkwalder $\mathrm{C}$, et al., Iron metabolism and the risk of restless legs syndrome in an elderly general population-the MEMO-Study, J Neurol, 2002;249:1195-9.

58 Benediktsdottir $B$, Janson $C$, Lindberg $E$, et al.. Prevalence of restless legs syndrome among adults in Iceland and Sweden lung function, comorbidity, ferritin, biomarkers and quality of life, Sleep Med, 2010:11:1043-8.

59. Earley CJ, Ponnuru P, Wang X, et al., Altered iron metabolism in lymphocytes from subjects with restless legs syndrome, Sleep, 2008;31:847-52.

60. Dowling P, Klinker F, Amaya F, et al., Iron-deficiency sensitizes mice to acute pain stimuli and formalin-induced nociception, J Nutr, 2009;139:2087-92

61. Dowling P, Klinker F, Stadelmann C, et al., Dopamine D3 receptor specifically modulates motor and sensory symptoms

in iron-deficient mice, J Neurosci, 2011:31:70-7.

62. Bianco LE, Unger EL, Earley CJ, et al., Iron deficiency alters the day-night variation in monoamine levels in mice, Chronobiol Int, 2009:26:447-63.

63. Bianco LE, Wiesinger J, Earley CJ, et al., Iron deficiency alters dopamine uptake and response to L-DOPA injection in Sprague-Dawley rats, J Neurochem, 2008:106:205-15.

64. Unger $E L$, Bianco $L E$, Jones $B C$, et al., Low brain iron effects and reversibility on striatal dopamine dynamics, Exp Neuro 2014;261:462-8

65. Jellen $L C$, Lu L, Wang $X$, et al., Iron deficiency alters expression of dopamine-related genes in the ventral midbrain in mice, Neuroscience, 2013 Nov 12;252:13-23.

66. Quiroz C, Pearson V, Gulyani S, et al., Up-regulation of striatal adenosine $A(2 A)$ receptors with iron deficiency in rats: effects on locomotion and cortico-striatal neurotransmission, Exp Neurol, 2010;224:292-8.

67. Rizzo G, Tonon C, Testa C, et al., Abnormal medial thalamic metabolism in patients with idiopathic restless legs syndrome, Brain, 2012:135:3712-20.

68. Allen RP, Barker PB, Horská A, et al., Thalamic glutamate/ glutamine in restless legs syndrome: increased and related to disturbed sleep, Neurology, 2013;80:2028-34.

69 Winkelman JW, Schoerning L, Platt S, et al., Restless legs syndrome and central nervous system gamma-aminobutyri acid: preliminary associations with periodic limb movements in sleep and restless leg syndrome symptom severity, Sleep Med, 2014;15:1225-30

70. Jiménez-Jiménez FJ, Alonso-Navarro H, Martínez $\mathrm{C}$, et al., The solute carrier family 1 (glial high affinity glutamate transporter), member 2 gene, SLC1A2, rs3794087 variant and assessment risk for restless legs syndrome, Sleep Med 2014;15:266-8.

71. Sun YM, Hoang T, Neubauer JA, et al., Opioids protect against substantia nigra cell degeneration under conditions of iron deprivation: a mechanism of possible relevance to the Restless Legs Syndrome (RLS) and Parkinson's disease, I Neurol Sci, 2011;304:93-101.

72. Allen RP, Mignot E, Ripley B, et al., Increased CSF hypocretin-1 (orexin-A) in restless legs syndrome, Neurology, 2002;59: $639-41$

73. Stiasny-Kolster K, Mignot E, Ling L, et al., CSF hypocretin-1 levels in restless legs syndrome, Neurology, 2003;61:1426-9.

4. Mignot E, Lammers GJ, Ripley B, et al., The role of cerebrospinal fluid hypocretin measurement in the diagnosis of narcolepsy and other hypersomnias, Arch Neurol, 2002;59:1553-62.

75. Balaban H, YıldıZ ÖK, Çil G, et al., Serum 25-hydroxyvitamin D levels in restless legs syndrome patients, sleep Med, 2012;13:953-7.

6. Oran M, Unsal C, Albayrak Y, et al., Possible association between vitamin $\mathrm{D}$ deficiency and restless legs syndrome, Neuropsychiatr Dis Treat, 2014;10:953-8.

77. Patton SM, Cho YW, Clardy TW, et al., Proteomic analysis of the cerebrospinal fluid of patients with restless legs syndrome/Willis-Ekbom disease, Fluids Barriers CNS, 2013:10:20

78. Baskol G, Korkmaz S, Erdem F, et al., Assessment of nitric oxide, advanced oxidation protein products, malondialdehyde, and thiol levels in patients with restless legs syndrome, Sleep Med, 2012;13:414-8.

. Patton SM, Ponnuru P, Snyder AM, et al., Hypoxia-inducible factor pathway activation in restless legs syndrome patients, Eur I Neurol, 2011;18:1329-35.

80. Clemens S, Sawchuk MA, Hochman S, Reversal of the circadian expression of tyrosine-hydroxylase but not nitric oxide synthase levels in the spinal cord of dopamine D3 receptor knockout mice, Neuroscience, 2005:133:353-7.

81. Winkelmann J, Lichtner P, Schormair B, et al., Variants in the neuronal nitric oxide synthase (nNOS, NOS1) gene are associated with restless legs syndrome, Mov Disord, 2008; 23: $350-8$.

82. Jiménez-Jiménez FJ, Alonso-Navarro $\mathrm{H}$, Martínez $\mathrm{C}$, et al., Neuronal nitric oxide synthase (nNOS, NOS1) rs693534 and rs7977109 variants and risk for restless legs syndrome, I Neural Transm, 2014 Oct 10. [Epub ahead of print]

83. Wetter TC, collado-Seidel V, Oertel $H$, et al. Endocrine rhythms in patients with restless legs syndrome, I Neurol, $2002 \cdot 249 \cdot 146-51$

84. Schilling C, Schredl M, Strobl P, et al., Restless legs syndrome: evidence for nocturnal hypothalamic-pituitary-adrenal system activation, Mov Disord, 2010;25:1047-52.

85. Tribl GG, Waldhauser F, Sycha T, et al., Urinary 6-hydroxymelatonin-sulfate excretion and circadian rhythm in patients with restless legs syndrome, J Pineal Res, 2003;35:295-6.

86. Koo BB, Feng P, Dostal J, et al., Alpha-melanocyte stimulating hormone and adrenocorticotropic hormone: an alternative approach when thinking

87. Bachmann $\mathrm{CG}$, Guth $\mathrm{N}$, Helmschmied $\mathrm{K}$, et al., Homocystein 
91. Chang $\mathrm{Y}$, Chang HW, Song $\mathrm{H}$, et al., Gray matter alteration in patients with restless legs syndrome: a voxel-based morphometry study Clin Imaging 2014 Aug 2. pii. S08997071(14)00178-8. doi:

92. Comley RA, Cervenka S, Palhagen SE, et al., A comparison of gray matter density in restess legs syndrome patients of gray matter density in restless legs syndrome patien and matched controls using voxel-based morphometry, J Neuroimaging, 2012;22:28-32.

93. Unrath A, Müller HP, Ludolph AC, et al., Cerebral white matter alterations in idiopathic restless legs syndrome, as measure by diffusion tensor imaging, Mov Disord, 2008;23:1250-5.

94. Connor JR, Ponnuru P, Lee BY, et al., Postmortem and imaging based analyses reveal CNS decreased myelination in restless legs syndrome, Sleep Med, 2011;12:614-9.

95. Walters AS, LeBrocq C, Dhar A, et al., International Restless Legs Syndrome Study Group, Validation of the International Restless Legs Syndrome Study Group rating scale for restless legs syndrome, Sleep Med, 2003;4:121-32.

96. Lanza G, Cantone M, Lanuzza B, et al., Distinctive patterns of cortical excitability to transcranial magnetic stimulation in obstructive sleep apnea syndrome, restless legs syndrome, insomnia, and sleep deprivation, Sleep Med Rev , 2015; 19: 39-50.

97. Stiasny-Kolster $\mathrm{K}$, Haeske $\mathrm{H}$, Tergau $\mathrm{F}$, et al., Cortical silent period is shortened in restless legs syndrome independently from circadian rhythm, Suppl Clin Neurophysiol, 2003;56:381-9.

98. Quatrale R, Manconi M, Gastaldo E, et al., Neurophysiologic study of corticomotor pathways in restless legs syndrome study of corticomotor pathways in rest
Clin Neurophysiol, 2003:114:1638-45.

99. Scalise A, Pittaro-Cadore I, Golob EJ, et al., Absence of postexercise and delayed facilitation of motor cortex excitability in restless legs syndrome: evidence of altered cortical plasticity? Sleep, 2006;29:770-5

100. Nardone R, Ausserer H, Bratti A, et al., Cabergoline reverses cortical hyperexcitability in patients with restless legs syndrome, Acta Neurol Scand, 2006;114:244-9.

101. Rizzo V, Aricò I, Mastroeni C, et al., Dopamine agonists restore cortical plasticity in patients with idiopathic restless legs syndrome, Mov Disord, 2009;24:710-5.

102. Scalise A, Pittaro-Cadore I, Janes F, et al., Changes of cortical excitability after dopaminergic treatment in restless legs syndrome, sleep Med, 2010;11:75-81.

103. Lanza G, Lanuzza B, Aricò D, et al., Direct comparison of cortical excitability to transcranial magnetic stimulation in obstructive sleep apnea syndrome and restless legs syndrome, Sleep Med, 2015:16:138-42. 104. Tergau F, Wischer S, Paulus W, Motor system excitability in patients with restless legs syndrome, Neurology, 1999;52:1060-3.

105. Entezari-Taher $\mathrm{M}$, Singleton $J R$, Jones $C R$, et al, Changes in excitability of motor cortical circuitry in primary restless legs syndrome, Neurology, 1999:53:1201-5.

106. Kutukcu Y, Dogruer E, Yetkin S, et al., Evaluation of periodic leg movements and associated transcranial magnetic stimulation parameters in restless legs syndrome, Muscl Nerve, 2006;33:133-7.

107. Gorsler A, Liepert J, Influence of cabergoline on motor excitability in patients with restless legs syndrome, J Clin Neurophysiol, 2007;24:456-60.

108. Rizzo V, Aricò I, Liotta G, et al., Impairment of sensorymotor integration in patients affected by RLS, J Neurol, 2010;257:1979-85.

109. Gündüz A, Adatepe NU, Kiziltan ME, et al., Circadian changes in cortical excitability in restless legs syndrome, J Neurol Sci, 2012;316:122-5.

110. Ahlgrén-Rimpiläinen $A$, Lauerma $H$, Kähkönen $S$, et al., Recurrent CSPs after transcranial magnetic stimulation of motor cortex in restless legs syndrome, Neurol Res int 2012:2012:628949.

111. Scalise A, Cadore IP, Gigli GL, Motor cortex excitability in restless legs syndrome, Sleep Med, 2004;5:393-6. 